\title{
Food safety in an international perspective
}

\author{
Hilde Kruse ${ }^{1}$
}

Published online: 24 May 2015

(C) The Author(s) 2015. Dieser Artikel ist auf Springerlink.com mit Open Access verfügbar.

Access to safe food is a basic individual right. Yet, as stated by Dr. Margaret Chan, Director-General of the World Health Organization (WHO), "food safety is a hidden, and often overlooked, problem” (Chan 2014). Indeed, foodborne disease represents a significant burden to public health throughout the world. Unsafe food can lead to a range of health problems, with new threats to food safety constantly emerging. Food that contains harmful bacteria, viruses, parasites or chemical substances is responsible for more than 200 diseases, both acute and chronic, ranging from diarrhoea to cancer. WHO estimates that the burden of foodborne disease is much higher than currently reported (WHO Regional Office for Europe 2015; WHO 2015a).

The human food chain is longer and more complex than ever before, and demographic, cultural, economic and environmental developments-globalized trade, travel and migration, ageing populations, changing consumer preferences and habits, industrialization and new technologies, emergencies, climate change and extreme weather events-are increasing foodborne health risks. Driven by consumer demand, people now have greater access to a wider variety of foods, produced out of season, transported across continents, processed for their

Hilde Kruse

HIK@euro.who.int

1 Programme Manager Food Safety, World Health Organization Regional Office for Europe, Copenhagen, Denmark convenience and increasingly eaten outside the home.

A failure in food safety at any link in the long and complex food chain-from the environment, through primary production, processing, transport, storage, catering or at home-can have significant health and economic consequences, which are augmented by the fact that contamination from a single source may become widespread and have international ramifications (WHO Regional Office for Europe 2015). Dr. Chan points out: "A local food safety problem can rapidly become an international emergency. Investigation of an outbreak of foodborne disease is vastly more complicated when a single plate or package of food contains ingredients from multiple countries" (WHO 2015a).

The increasing public health concern over antimicrobial resistance is also a food-safety issue that must be addressed (Kruse and Racioppi 2011; WHO 2015c). Antibiotic use in food animals-for treatment, disease prevention or growth promotion-is considered to spread resistant bacteria and resistance genes from food animals to humans through the food-chain (Kruse and Racioppi 2011).

Current surveillance and reporting systems for foodborne disease are limited and detect only a small fraction of cases. This underreporting is greater in countries with less advanced laboratory capacities and less developed surveillance systems. Better data and improved information-sharing are needed to respond effectively to risks (WHO Regional Office for Europe 2015).

In an increasingly interconnected world, international collaboration and information-sharing is 
needed to respond effectively to foodborne health risks. Furthermore, for cost-efficient prevention and control of foodborne diseases, sectors such as public health, animal health and agriculture must collaborate both nationally and internationally, through effective communication, information-sharing and joint action. As stated by Dr. Zsuzsanna Jakab, WHO Regional Director for Europe: “Today, the journey from where our food comes from to how it ends on our plates is longer and more complex than ever before. Food-safety risks exist at every step. Our food safety and control systems must adapt and work together across sectors, along the entire food chain" (WHO Regional Office for Europe 2015). Health 2020, the European policy for health and well-being, underlines the principle of intersectoral action to promote health and the application of a "health-inall-policies" approach (WHO 2015d).

WHO dedicated its World Health Day 2015 to food safety, under the slogan, "From farm to plate, make food safe", highlighting the challenges and opportunities associated with food safety (WHO 2015a). This Day, celebrated on April 7th, represented an exceptional occasion to recognize the important food safety role we all have, and to strengthen collaboration and coordination among various sectors, in order to prevent, detect and respond to foodborne diseases. Event and activities were held throughout the world to raise awareness of food safety and prevention of foodborne disease.

On the occasion of the World Health Day 2015, WHO issued some preliminary findings from a broader ongoing analysis of the global burden of foodborne diseases. The full results of this research, being undertaken by WHO's Foodborne Disease Burden Epidemiology Reference Group (FERG) (WHO 2015b), are expected to be released in October 2015.

Some important results are related to enteric infections caused by viruses, bacteria and protozoa that enter the body by ingestion of contaminated food. The initial FERG figures from 2010 show that:

- there were an estimated 582 million cases of 22 different foodborne enteric diseases and 351,000 associated deaths;

- the enteric disease agents responsible for most deaths were Salmonella typhi (52,000 deaths), enteropathogenic Escherichia coli $(37,000)$ and norovirus $(35,000)$;

- the African Region recorded the highest disease burden for enteric foodborne disease, followed by South-East Asia;
- over $40 \%$ of people suffering from enteric diseases caused by contaminated food were children aged under 5 years.

In order to combat foodborne disease and improve food safety, WHO calls on policy-makers to:

- build and maintain adequate food safety systems and infrastructures, including laboratory capacities and surveillance and reporting systems;

- respond to and manage food safety risks along the entire food chain, including during emergencies;

- foster multisectoral collaboration among public health, animal health, agriculture and other sectors for better communication, informationsharing and joint action;

- integrate food safety into broader food policies and programmes (e.g. nutrition and food security);

- think globally and act locally to ensure that food produced domestically is as safe as possible internationally.

WHO, in collaboration with its partners at regional and international levels, is supporting countries in their efforts to address foodborne health threats efficiently, facilitating information-sharing and raising awareness with the overall aim of reducing and preventing foodborne threats to public health across the globe. The development of robust food safety systems that drive collective government and public action to safeguard against chemical or microbial contamination of food is crucial. Building capacity in foodborne disease detection, surveillance and response is the key to strengthen the national food safety systems. Codex Alimentarius international food standards, guidelines and codes of practice contribute to the safety, quality and fairness of international food trade, and countries are encouraged to actively participate in Codex work (http://www.codexalimentarius.org/codex-home/en/).

The joint WHO/Food and Agriculture Organisation International Food Safety Authorities Network (INFOSAN) helps to ensure effective and rapid communication during food safety emergencies (WHO 2015e).

At the consumer end of the food supply chain, the public plays important roles in promoting food safety and ensuring safe food handling and preparations. WHO's Five keys to safer food explain the basic principles that each individual should know all over the world to prevent foodborne diseases (WHO 2015f).

Everyone has a role to play to enhance food safety. 
Open Access This article is distributed under the terms of the Creative Commons Attribution 4.0 International License (http://creativecommons.org/licenses/by/4.0/), which permits unrestricted use, distribution, and reproduction in any medium, provided you give appropriate credit to the original author(s) and the source, provide a link to the Creative Commons license, and indicate if changes were made.

\section{References}

Chan M (2014) Food safety must accompany food and nutrition security. Lancet 384(9958):1910-1911. 10.1016/S01406736(14)62037-7

Codex Alimentarius (2015). http://www.codexalimentarius.org/ codex-home/en/. Accessed 18 May 2015

Kruse H, Racioppi F (2011) Tackling antibiotic resistance from a food safety perspective in Europe. WHO Regional Office for Europe, Copenhagen. http://www.euro.who.int/_data/ assets/pdf_file/0005/136454/e94889.pdf. Accessed 18 May 2015

WHO (2015a) World Health Day 2015: From farm to plate, make food safe. World Health Organization, Geneva. http://www.who.int/mediacentre/news/releases/2015/foodsafety/en/. Accessed 18 May 2015
WHO (2015b) Burden of foodborne disease. World Health Organization, Geneva. http://www.who.int/foodsafety/ areas_work/foodborne-diseases/ferg/en/. Accessed 18 May 2015

WHO (2015c) Draft global action plan on antimicrobial resistance. World Health Organization, Geneva. http:// www.who.int/drugresistance/global_action_plan/en/. Accessed 18 May 2015

WHO (2015d) Regional office for Europe. Health 2020: the European policy for health and well-being. WHO Regional Office for Europe, Copenhagen. http://www.euro.who.int/ en/health-topics/health-policy/health-2020-the-europeanpolicy-for-health-and-well-being. Accessed 18 May 2015

WHO (2015e) Infosan. World Health Organization, Geneva. http://www.who.int/foodsafety/areas_work/infosan/en/. Accessed 18 May 2015

WHO (2015f) The five keys to safer food programme. World Health Organization, Geneva. http://www.who.int/ foodsafety/areas_work/food-hygiene/5keys/en/. Accessed 18 May 2015

WHO Regional Office for Europe (2015) Complex food chain increases food safety risks. WHO Regional Office for Europe, Copenhagen. http://www.euro.who.int/en/mediacentre/sections/press-releases/2015/complex-food-chainincreases-food-safety-risks. Accessed 18 May 2015 